\title{
New materials, new horizons
}

\author{
Nadya Anscombe talks to Stephen Eglash of the Precourt Institute for Energy at Stanford University in the USA \\ about his vision for the green photonics sector.
}

What does 'green photonics' entail? The term 'green photonics' describes any device or process that uses photonics in a sustainable way. This could include optoelectronic devices that are more efficient than previous models, or the use of photonic technology to improve the efficiency of a particular process. The four main areas of green photonics are photovoltaics, solid-state lighting, manufacturing and communications technology. The green photonics market is expanding for two reasons: green technology is receiving increasing attention thanks to our growing concern for the environment; and photonic technologies often provide green, efficient solutions that can give companies a competitive advantage.

\section{Which areas hold the} greatest opportunities?

Solar energy is hugely exciting. Highefficiency solar cells are becoming greener by using new manufacturing techniques and materials, while greener, less-efficient technologies such as earth-abundant inorganic and organic cells are becoming more efficient thanks to intensive research and development. The rate of growth in solid-state lighting is also tremendous. I think we are now reaching a tipping point in these industries that will reduce costs considerably, leading to widespread adoption. Sensors and coatings are also fascinating areas for green photonics. Although not all sensors are photonic, many applications have been enabled by photonic technologies. We are rapidly approaching a scenario in which cheap sensors, combined with cheap chips and cheap wireless connectivity, can be used to make an interconnected world that is extremely efficient. For example, an energyefficient home could sense when clouds are obscuring solar cells on the roof and decide to switch off the refrigerator for a short while to conserve energy. Photonic sensors are also being used to regulate emissions in process control and to monitor wind turbines to make them more efficient. In the building industry, optical coatings are being used on windows to conserve energy and insulate buildings.

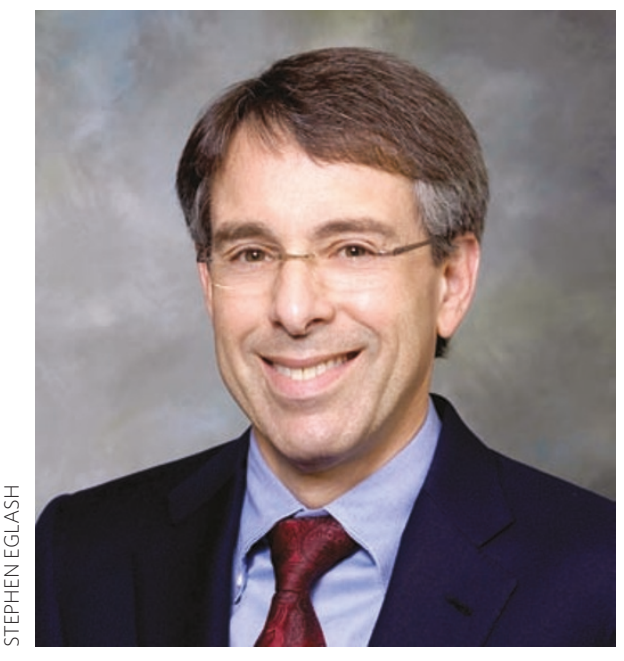

Stephen Eglash: "Solid-state lighting can make a real contribution to our impact on climate change."

\section{What has enabled green photonics?}

The key to all advances in green photonics is the engineering of new, efficient materials and processes. For example, we would not have been able to improve the efficiency of solar cells so dramatically without an understanding of how semiconductor materials work at the nanoscale. I believe that advances in materials science and chemical engineering over the next decade will bring about enormous progress in areas such as energy conversion, catalysis and green photonics in general. Materials today are developed for specific purposes, and this gives us the opportunity to make them as efficient and environmentally friendly as possible for those particular applications.

\section{Can green photonics really make a} significant impact?

I believe that the use of solid-state lighting can make a real contribution to our impact on climate change. This impact, however, will not be immediate. History tells us that new generations of lighting technology do not decrease energy useage, but rather use the same amount of energy to produce more light. There are still billions of people around the world who do not have access to electric lighting. Introducing solid-state lighting to these people would result in a smaller increase in future emissions than if traditional incandescent lighting was used. Although it is still important for the developed world to adopt solid-state lighting, I believe it is the developing world that will see the most benefit from this technology.

\section{What does the future hold for green photonics?}

I think the labels of manufactured goods will eventually include information about their environmental impact. Many supermarket products display their country of origin, and some even provide information on their carbon footprint. In the future, manufactured products may provide information on how much energy was used, how much water was consumed or how much $\mathrm{CO}_{2}$ was generated during the manufacturing process. This will enable customers to make informed choices, which together with the increasing concern about climate change, will lead to further growth in the green photonics industry.

\section{Are there any barriers to growth?} New technologies often need help to drive their initial uptake. The idea is not to prop-up weak technologies, but rather to help young technologies along the learning curve. This worked for solar technology, and governments need to continue supporting new, green photonic technologies.

Continued investment in basic research and development is important because it is our understanding of new materials and processes that has enabled this market. Chinese support for research, development and manufacturing is helping to establish China as a leader in renewable energy. Governments may also need to provide financial incentives and eliminate barriers such as regulations and restrictions. This worked for Germany, for example, when it implemented feed-in tariffs for photovoltaic electricity generation. Although this was an expensive investment, Germany has gained energy independence and is now a leader in renewable energy.

\section{NADYA ANSCOMBE}

Nadya Anscombe is a freelance journalist based in the United Kingdom. 